\title{
Chemokine (C-X-C Motif) Ligand 10 Measurement
}

National Cancer Institute

\section{Source}

National Cancer Institute. Chemokine (C-X-CMotif) Ligand 10 Measurement. NCI

Thesaurus. Code 112238.

The determination of the amount of chemokine (C-X-C Motif) ligand 10 present in a sample. 